\title{
INTERSECÇÕES ENTRE SAÚDE E AMBIENTE EM ESCOLAS ESTADUAIS DA BAIXADA FLUMINENSE: UMA ANÁLISE INICIAL DAS PRÁTICAS DOCENTES
}

\author{
Patrícia Sacramento $^{1}$, Felipe Rodrigues ${ }^{2}$, Flavia Araujo ${ }^{3}$, Maylta Brandão dos Anjos ${ }^{4}$ e \\ Giselle Rôças ${ }^{4}$. \\ ${ }^{1}$ UFF, Bolsista de Iniciação Científica do IFRJ Nilópolis. \\ ${ }^{2}$ IFRJ, Bolsista de Iniciação Científica do IFRJ Nilópolis. \\ ${ }^{3}$ UFF, Docente do Departamento de Educação. \\ ${ }^{4}$ IFRJ Nilópolis, Docente do Programa de Pós-Graduação Stricto Sensu em Ensino de Ciências.
}

\begin{abstract}
Resumo
O trabalho analisa o desenvolvimento dos temas educação, saúde e ambiente no currículo de escolas públicas de ensino médio e suas práticas pedagógicas. O cenário do estudo é composto por quatro escolas estaduais localizadas na Baixada Fluminense no município de Nilópolis. O critério utilizado para escolha dessas escolas foi a média obtida no Exame Nacional do Ensino Médio (ENEM). A abordagem da pesquisa é qualitativa. Os professores dessas escolas participaram de oficinas desenvolvidas no IFRJ, onde foram propostos meios didáticos para o trabalho com saúde e ambiente. As escolas receberam o apoio didático de livros ligados aos temas, doados pelo IFRJ com apoio da FAPERJ, dispondo assim de outros recursos para desenvolvimento de novas atividades. Num segundo momento, realizamos visitas às escolas para verificar o desenvolvimento das atividades propostas pela pesquisa. As visitas serviram de base para as demais etapas da pesquisa. As principais motivações apontadas para a inserção dos temas transversais presentes nos PCN foram: a presença na mídia acerca dessa temática e a importância de orientação dos alunos. Entretanto, mesmo com a doação dos livros escolhidos pelas escolas e professores, até o momento, em apenas uma das instituições foi desenvolvido novos trabalhos associando os temas saúde e ambiente a partir do uso dos livros.
\end{abstract}

Palavras-chave: ensino médio; práticas docentes; saúde e ambiente.

\begin{abstract}
This qualitative study aims to analyze the development of education issues, health and environment in the curriculum of high school public schools and their teaching practices. It was performed in four schools located in the Baixada Fluminense located in Nilópolis city. The criterion used to choose them was the average obtained in the National Examination of Secondary Education (ENEM). Voluntary teachers participated in workshops conducted in IFRJ where teaching methods were proposed to work with health and environment. The schools received the support of didactic books related to themes, donated by IFRJ with support from FAPERJ and therefore have other resources for developing new activities. We also conducted visits to schools to monitor the development of the activities proposed by the research. The visits formed the basis for the remaining stages of the research.
\end{abstract}

Keywords: Environmental and Health Education; Paradidatic Textbook; Science Teaching 


\section{Introdução}

Usualmente observa-se a agregação da Promoção e da Educação em Saúde em projetos escolares, acadêmicos, sociais, de divulgação científica e mesmo de saúde. Candeias (1997), entretanto, alerta para as constantes confusões entre estes termos, as quais vêm acarretando entraves no campo teórico e prático das ações de saúde. Segundo a autora, Educação em Saúde engloba:

quaisquer combinações de experiências de aprendizagem delineadas com vistas a facilitar ações voluntárias conducentes à saúde. A palavra combinação enfatiza a importância de combinar múltiplos determinantes do comportamento humano com múltiplas experiências de aprendizagem e de intervenções educativas (CANDEIAS, 1997, p. 210).

Enquanto Promoção de Saúde aborda:

(...) uma combinação de apoios educacionais e ambientais que visam a atingir ações e condições de vida conducentes à saúde. Combinação refere-se à necessidade de mesclar os múltiplos determinantes da saúde (fatores genéticos, ambiente, serviços de saúde e estilo de vida) com múltiplas intervenções ou fontes de apoio. Educacional refere-se à Educação em Saúde tal como acima definida (Candeias, 1997, p. 210).

A Educação para a Saúde é considerada como uma importante estratégia de Promoção da Saúde, fundamental para a consolidação da cidadania. A sua inserção no currículo das escolas de educação básica atende à demanda social, considerando-se a necessidade de desenvolvimento da consciência sanitária da população e dos governantes para que o direito à saúde seja encarado como prioridade. Sendo dos princípios estabelecidos pela OMS para alcançar tais objetivos a concepção holística, a intersetorialidade, o empoderamento, a participação social, a eqüidade, as ações multiestratégicas e a sustentabilidade (CERQUEIRA apud SICOLI e NASCIMENTO, 2003).

No Brasil, a partir da década de 90, o trabalho educativo em saúde vem avançando com a incorporação de novas concepções teóricas. Ancoradas num referencial crítico, as novas abordagens contribuem para por em relevo a relação entre saúde, meio ambiente e transformação social. Estas discussões, que propiciam uma maior amplitude podem contribuir para superação do tradicional enfoque sanitarista, 
favorecendo a aquisição de conhecimentos que levem o educando a questionar e refletir acerca dos fatores que condicionam a vida.

Após a aprovação da Lei de Diretrizes e Base da Educação Nacional n ${ }^{\circ}$ 9394/96, foram elaboradas novas diretrizes os currículos da educação básica. A saúde e meio ambiente integra os Temas Transversais propostos nos Parâmetros Curriculares Nacionais (PCN), elaborados pelo Ministério da Educação. De acordo este documento, os temas transversais constituem temáticas sociais importantes para formação da cidadania que devem ser abordadas na escola por todas as disciplinas que compõem a matriz curricular da educação básica. Entretanto, apesar das orientações emanadas pelo ministério, observa-se que estas temáticas ainda são tratadas de forma desarticulada e constituem objeto de atividades pontuais, sendo apresentadas através das disciplinas específicas e/ou em feiras de ciências, semana do conhecimento ou semana de saúde.

Partindo desses pressupostos, o presente trabalho teve como objetivo analisar o desenvolvimento dos temas educação, saúde e ambiente na prática de docentes de escolas públicas de ensino médio. O foco da investigação dirigiu-se para a Baixada Fluminense, considerando os graves problemas de saneamento e de saúde pública existentes no conjunto de municípios. Assinala-se que essa região constitui-se como uma das áreas metropolitanas mais populosas no Estado do Rio de Janeiro, onde são encontradas altas taxas de doenças acarretadas por problemas de saneamento básico.

\section{Metodologia}

A pesquisa está sendo realizada em quatro escolas de ensino médio da rede pública estadual do município de Nilópolis, Rio de Janeiro. O objetivo é verificar como os temas saúde e ambiente vem sendo trabalhados em escolas localizadas em áreas carentes em termos de saneamento ambiental e recursos educacionais. $\mathrm{O}$ critério utilizado para escolha dessas escolas foi a média obtida no Exame Nacional do Ensino Médio (ENEM). Foram escolhidas duas escolas que obtiveram as maiores e as duas com as menores notas. As quatro escolas possuem aulas em três turnos (manhã, tarde e noite).

A pesquisa, de cunho qualitativo, envolveu diversos percursos metodológicos. Os percursos metodológicos foram delineados de acordo com as diferentes etapas do trabalho, o qual apresenta cunho qualitativo, sendo necessário o envolvimento de diversos procedimentos metodológicos. 
As estratégias utilizadas para consecução da pesquisa se constitui em questionários com perguntas abertas e fechadas aplicado a professores e alunos, depoimentos de professores e coordenadoras pedagógicas, análise dos Projetos Políticos Pedagógicos e acompanhamento do desenvolvimento de atividades desenvolvidas pelos docentes a partir do livros didáticos doados às escolas.

Em um primeiro momento foram aplicados questionários a todos os professores do ensino médio das quatro escolas participantes da pesquisa a fim de obtermos dados iniciais das práticas docentes realizadas nas escolas sobre os temas saúde e ambiente. O questionário foi composto por perguntas abertas e fechadas, totalizando 14 perguntas, com dados pessoais (referentes a idade, sexo, formação), dados referentes a escola como disciplina que leciona, recursos didáticos disponibilizados pela instituição e perguntas ligadas a forma como o temática estudada é trabalhada.

Dos 20 questionários entregues em cada uma das quatro escolas, totalizando 80, tivemos o retorno de 38 para serem analisados. A partir dessa análise primeira foi possível um diagnóstico inicial das escolas, possibilitando a aplicação de metodologias diferenciadas em outras etapas do projeto que ainda está em andamento. Os professores apontaram algumas dificuldades para discussão da temática e algumas possíveis soluções como, por exemplo, realização de palestras, cursos de capacitação e recursos didáticos. Dessa forma, em um segundo momento, foi realizada uma oficina no IFRJ com professores voluntários dessas escolas, e também foram doados livros escolhidos por eles e escola referentes ao tema saúde e ambiente. Foram realizadas também palestras, ligadas ao ensino de ciências, pelos alunos do mestrado do IFRJ nessas quatro instituições e no decorrer do projeto novas palestras serão realizadas.

Atualmente estamos realizando visitas às escolas para verificar o desenvolvimento das atividades propostas pela pesquisa aos professores, com o uso dos livros doados, e a sua recepção pelos alunos. A partir dessas visitas solicitamos às diretoras o Projeto Político Pedagógico (PPP) para serem analisados e aplicamos também questionários aos alunos para termos dados sobre sua opinião a respeito da discussão do tema na escola.

\section{Resultados e Discussão}

\section{Questionários iniciais aplicado aos docentes}


A partir da análise dos questionários iniciais aplicados aos professores, de diferentes disciplinas do ensino médio, realizamos um diagnóstico que pode ser observado na tabela um (1). Podemos perceber que em todas as escolas, a maior parte desses profissionais tem longa experiência no magistério. Nas escolas B e D todos os professores têm algum tipo de especialização, sendo em B dois na área ambiental e dois na área de saúde. Nas escolas A e C a maioria dos professores também têm algum tipo de especialização, sendo um da escola $\mathrm{C}$ na área ambiental, mas não em sua totalidade com nas demais citadas.

Tabela 1 - Dados percentuais relativos ao perfil dos docentes das escolas envolvidas na pesquisa.

\begin{tabular}{|c|c|c|c|c|}
\hline Variável & Escola A & Escola B & Escola C & Escola D \\
\hline \multirow{9}{*}{ Idade (anos) } & Entre 20 e 30 & Entre 20 e 30 & Entre 20 e 30 & Entre 20 e 30 \\
\hline & $20 \%$ & $12,5 \%$ & $23,6 \%$ & $12,5 \%$ \\
\hline & Entre 31 e 40 & Entre 31 e 40 & Entre 31 e 40 & Entre 31 e 40 \\
\hline & $20 \%$ & $37,5 \%$ & $23,6 \%$ & $25 \%$ \\
\hline & Entre 41 e 50 & Entre 41 e 50 & Entre 41 e 50 & Entre 41 e 50 \\
\hline & $60 \%$ & $25 \%$ & $35,3 \%$ & $62,5 \%$ \\
\hline & Entre 51 e 60 & Entre 51 e 60 & Entre 51 e 60 & Entre 51 e 60 \\
\hline & $0 \%$ & $25 \%$ & $11,7 \%$ & \\
\hline & & & $\begin{array}{l}\text { Não respondeu } \\
5.9 \%\end{array}$ & \\
\hline \multirow[t]{2}{*}{ Sexo } & $60 \%$ feminino & $50 \%$ feminino & $82,3 \%$ feminino & $87,5 \%$ feminino \\
\hline & $\begin{array}{l}40 \% \\
\text { masculino }\end{array}$ & $\begin{array}{l}50 \% \\
\text { masculino }\end{array}$ & $17,6 \%$ masculino & $12,5 \%$ masculino \\
\hline \multirow{9}{*}{$\begin{array}{l}\text { Tempo de } \\
\text { formação } \\
\text { (anos) }\end{array}$} & $\begin{array}{llll}\text { Entre } & 1 & \text { e } & 10 \\
20 \% & & & \end{array}$ & $\begin{array}{l}\text { Entre } 1 \text { e } 10 \\
25 \%\end{array}$ & $\begin{array}{llll}\text { Entre } & 1 & \text { e } & 10 \\
23,6 \% & & & \end{array}$ & $\begin{array}{llll}\text { Entre } & 1 & \text { e } & 10 \\
25 \% & & & \end{array}$ \\
\hline & Entre 11 e 20 & Entre 11 e 20 & Entre 11 e 20 & Entre 11 e 20 \\
\hline & $20 \%$ & $25 \%$ & $29,4 \%$ & $37,5 \%$ \\
\hline & Entre 21 e 30 & Entre 21 e 30 & Entre 21 e 30 & Entre 21 e 30 \\
\hline & $60 \%$ & $25 \%$ & $29,4 \%$ & $25 \%$ \\
\hline & Entre 31 e 40 & Entre 31 e 40 & Entre 31 e 40 & Entre 31 e 40 \\
\hline & $0 \%$ & $25 \%$ & $5,9 \%$ & \\
\hline & & & Não respondeu & Não respondeu \\
\hline & & & $11,7 \%$ & $12,5 \%$ \\
\hline \multirow{4}{*}{ Especialização } & $\begin{array}{l}\text { Lato sensu } \\
60 \%\end{array}$ & $\begin{array}{l}\text { Lato sensu } \\
100 \%\end{array}$ & $\begin{array}{ll}\text { Lato } & \text { sensu } \\
88,2 \% & \end{array}$ & $\begin{array}{l}\text { Lato sensu } \\
100 \%\end{array}$ \\
\hline & & & Mestrado 17,7\% & Mestrado $12,5 \%$ \\
\hline & & & & Doutorado \\
\hline & & & & $12,5 \%$ \\
\hline
\end{tabular}


apontaram principalmente televisão e data show. As escolas possuem ainda, segundo os docentes, biblioteca, laboratório de informática e ciências e salas multimídia.

A análise dos dados relativos aos trabalhos com saúde e ambiente foi feito em computo único, e não separado por instituição, para permitir melhor percepção da temática nessa parte inicial do estudo. Em relação à presença do tema saúde e ambiente $89,4 \%$ dos professores disseram que a escola aborda a temática de forma associada.

A principal motivação apontada pelos professores para a inserção da discussão sobre saúde e ambiente nas aulas, foi os temas transversais propostos nos PCN com $30,1 \%$ de citação. Os docentes citaram também o fato destes temas estarem presentes na mídia, além de assinalarem a importância de orientar os alunos com $26 \%$, devido às orientações curriculares apresentou apenas $12,3 \%$ de citação e outros 5,6\%.

Apenas $21 \%$ dos entrevistados afirmaram ter dificuldade em discutir o tema saúde e ambiente nas aulas. Os outros $79 \%$ disseram não ter dificuldade. Entretanto, mesmo os que dizem não ter dificuldade deram opinião sobre o que dificulta a discussão, como pode ser visto na figura1. Entre outros apontam, por exemplo, falta de preparo do professor e pouco conhecimento sobre o assunto. Afirmam ainda que a melhor forma de solucionar as dificuldades, apontadas, seria a realização de palestras sobre o tema na escola com $29,5 \%$ de marcação e também a disponibilidade de recursos didáticos, com 13,6 \% (tabela 2). Nas repostas dos docentes, sobressai a ênfase na necessidade de formação continuada, de acesso a oportunidades que propiciem o desenvolvimento profissional.

Esta preocupação motivou o IFRJ a organizar, uma oficina e palestras que, ministradas pelos alunos do mestrado, buscaram discutir as relações entre saúde e ambiente e, ainda, o ensino de ciências nas escolas públicas.

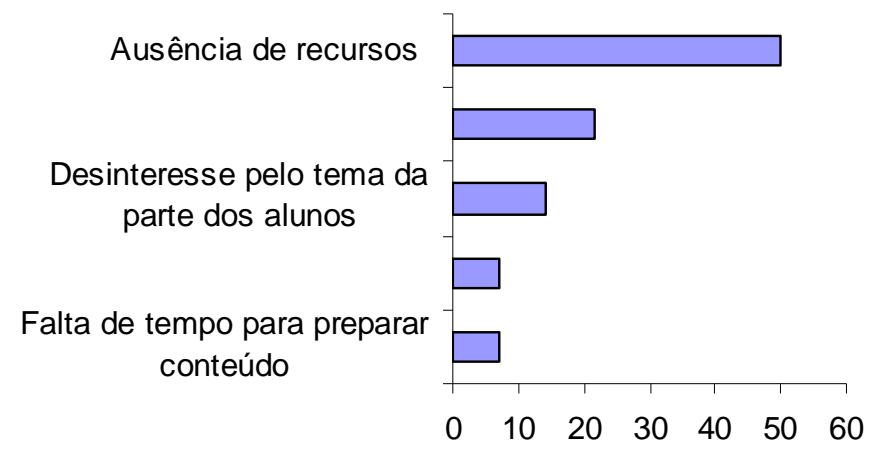


Figura 2: Pontos que dificultam a discussão da temática saúde e ambiente pelos docentes

Tabela 2: Melhores formas para solucionar as dificuldades na discussão da temática saúde e ambiente.

\begin{tabular}{l|c}
\multicolumn{1}{c|}{ Formas } & Porcentagem \\
\hline Realização de palestras sobre o tema na escola & 29,5 \\
\hline Interação entre professores de diferentes áreas & 25 \\
\hline Cursos de capacitação & 18,3 \\
\hline Disponibilidade de recursos didáticos & 13,6 \\
\hline Não respondeu & 9,1 \\
\hline
\end{tabular}

\section{Palestra e oficinas}

A partir das sugestões, para ajudar em suas dificuldades, apontadas pelos professores o IFRJ, através dos alunos de mestrado, realizou palestras para os docentes dessas instituições com o intuito de estimular cada vez mais a discussão sobre saúde e ambiente e outros tópicos voltados para o ensino de ciências nas escolas, permitindo assim uma maior orientação dos alunos e conscientização que poluição, agravos ao meio ambiente podem repercutir em problemas de saúde pública. Novas palestras ligadas à saúde ainda serão realizadas nas escolas no decorrer do projeto.

As oficinas foram realizadas aos sábados com professores voluntários das quatro escolas participantes do projeto e professores de outras escolas. Os professores eram de diferentes áreas como letras, química, biologia e educação física, por exemplo. A maioria era bastante participativa e compartilhava com os demais suas experiências. $\mathrm{O}$ objetivo da oficina foi fortalecer competências, habilidades e atitudes pedagógicas de professores que atuam nas salas de aula das escolas da rede pública, possibilitando aos docentes refletirem acerca dos problemas e questões surgidos no ensino de ciências. A ação proposta buscou promover o aprofundamento de saberes disciplinares, a discussão de caminhos metodológicos e a produção de material didático de caráter interdisciplinar e lúdico. Durante o seu desenvolvimento foi proposto que os professores elaborassem um projeto final voltado para recursos didáticos. Surgiram diferentes idéias como: vídeos interativos, programas de computador voltado para o ensino de ciências e 
cartilha interativa. Esses dados estão presentes em livro, gerado a partir desse evento, que será publicado e disponibilizado para escolas da baixada fluminense.

Através da oficina foram doados às quatro escolas, livros ligados ao tema saúde e ambiente, que foi escolhido pelas próprias instituições em conjunto com os professores participantes da oficina. O intuito foi suprimir um dos pontos apontados pelos professores como dificuldade na discussão da temática, que foi recursos didáticos. Com esses livros foi sugerida a realização de novas atividades sobre saúde e ambiente com os alunos, para ajudá-los assim na percepção da ligação entre esses tópicos e na aquisição de novos aprendizados.

Quando questionados se realizam trabalhos interdisciplinares sobre o tema $68,4 \%$ dos professores falaram que realizam e 31,5\% disseram que não o fazem. Os professores que não trabalham de forma interdisciplinar disseram que o que dificulta esse tipo de trabalho são os dias de aula diferentes dos outros docentes, falta de interesse dos alunos, falta de planejamento, falta de tempo, falta de interação entre docentes, sendo a falta de planejamento o elemento mais apontado pelos professores.

Noventa e dois por cento dos entrevistados falaram que a instituição realiza algum tipo de evento que aborde o tema saúde e ambiente como: feiras, seminários, palestras, exposições, entre outros. Desses $21,1 \%$ disseram que o grau de interesse apresentado pelos alunos nesses eventos é muito bom, 60,5 \% disseram ser bom, 10,5\% disseram ser regular e 7,9\% não responderam. Ou seja, há interesse por parte dos discentes pelo tema o que é um ponto positivo na motivação para uma abordagem continua desse tema importante na escola de diferentes formas, não só restrita a sala de aula e de modo contextualizado com a realidade da comunidade escolar.

Paiva (apud, Fonseca, p.19), refere que a escola é um campo social permeável às abordagens transdisciplinares e à profusão de abordagens de diferentes correntes teóricas em todas as áreas do conhecimento. Portanto, a escola é um território privilegiado para a incorporação de conhecimentos sobre saúde, assim como a possibilidade de transformar o atual quadro de vulnerabilidade social em que muitos jovens brasileiros vivem atualmente.

A partir dessa análise o dado que tivemos foi que a temática saúde e ambiente está inserida nas quatro escolas participantes da pesquisa, seja através de eventos e projetos, como em sala de aula, por professores de diferentes disciplinas. E que esses 
professores gostariam que fosse disponibilizado cursos e recursos didáticos para ajudar na discussão do tema em sala.

Entretanto, quando foi divulgado nas escolas sobre a oficina a ser realizada no IFRJ aos sábados, cuja localização é próxima as quatro escolas participantes da pesquisa, a procura por parte dos professores não foi muito grande. Talvez em parte por ser em finais de semana. O número de professores voluntários para desenvolvimento de novas atividades ligadas ao tema, a partir dos livros doados, também foi reduzida. $\mathrm{Na}$ escola A tivemos apenas dois professores (um de biologia e uma de espanhol). Na escola B uma das professoras se desligou dessa instituição e apenas um professor (de geografia), que não participou da oficina, aceitou trabalhar com os livros. Na escola $\mathrm{C}$ dois professores (ambos de biologia). Na escola D a professora que se mostrou interessada pela atividade foi transferida e no decorrer de várias visitas ainda não havia professores voluntários, em conversa com a coordenadora pedagógica ela informou que há muitos projetos sendo desenvolvidos na escola e por isso a dificuldade no desenvolvimento de uma nova atividade. Até o momento a única escola que realizou no ano letivo de 2009 atividade com os livros ligado a temática saúde e ambiente foi a escola B . Onde o professor de geografia trabalhou o tema da seguinte forma segundo suas palavras: “Os livros foram utilizados pelos alunos através de leituras sistemáticas e a partir disso, foi possível debater incessantemente o tema. Além do livro, foram utilizados três documentários tratando sobre o tema meio ambiente”. (O livro utilizado foi de: LEITE, Marcelo. Meio ambiente e sociedade. Editora Ática, 2009. O DVD utilizado foi- Desafio Mudanças Climáticas, 2009)

Como diz Freire (apud, Pereira, p.1532), é através do diálogo que se dá a verdadeira comunicação, onde os interlocutores são ativos e iguais. A comunicação é uma relação social igualitária, dialogal, que produz conhecimento.

O trabalho foi desenvolvido com alunos da turma do terceiro ano do ensino médio permitindo aos alunos o acordo entre a saúde e a qualidade do meio ambiente. Em conformação com o professor: "Com a utilização desses recursos foi possível compreender que meio ambiente e saúde são indissociáveis”. Professor de geografia.

A partir da fala do professor podemos perceber que com o debate realizado em sala de aula os alunos puderam perceber melhor a sua realidade associando assim a conexão entre o meio ambiente e sua saúde. 


\section{Questionários aplicados aos discentes}

Em um segundo momento da pesquisa, além do acompanhamento das atividades elaboradas pelos professores, verificou-se, através da aplicação de questionários, como foi a recepção dos alunos pela atividade desenvolvido pelos docentes e o aprendizado obtido. Como apenas a escola B chegou a essa etapa, até o momento, será apresentado apenas os dados dessa escola.

O questionário foi aplicado para os alunos do terceiro ano do ensino médio da escola A durante o intervalo de aula, havia 13 alunos em sala e todos responderam ao questionário, sendo 11 do sexo feminino e 2 do sexo masculino, com idades entre 17 e 20 anos.

Ao serem questionados sobre quais disciplinas abordam o tema saúde e ambiente em sala de aula, os alunos apontaram principalmente geografia e matemática, cujos professores falam sobre o assunto durante as suas aulas. Esses professores realizam projetos principalmente sobre a temática ambiental na escola (dado obtido através de conversa com esses professores e com a coordenadora da escola). O principal recurso didático utilizado por eles são livros didáticos e televisão, segundo os alunos.

Ao perguntar se os alunos tiverem interesse na leitura dos livros doados sobre o tema saúde e ambiente apenas um disse que não e um não respondeu a essa pergunta; os demais alunos tiveram interesse pela leitura e acharam o livro bom. Todos os alunos, inclusive o que não teve interesse em ler o livro, disseram que o livro e o trabalho desenvolvido pelo professor os ajudaram em ter mais conhecimentos sobre saúde e ambiente. E apontou a informação como a principal importância de a escola abordar a temática. Sendo essa feita principalmente através de trabalhos e debates em sala de aula como feito pelo professor de geografia.

Um ponto curioso que pode ser percebido com o questionário é que mesmo tendo gostado e achado importante a discussão do tema saúde e ambiente na escola dos 13 alunos que responderam as perguntas 4 disseram que não gostaria que o tema fosse abordado outras vezes. Talvez em função da realização de trabalho, uma vez que sugeriram que o tema ao ser abordado novamente fosse principalmente por meio de filmes, documentários e palestras.

Em relação aos PPP os mesmos estão sendo analisados, mas somente duas escolas (A e B) os disponibilizaram para análise, as outras duas alegaram que a análise deveria ser feita na própria instituição escolar. 


\section{Considerações Finais}

A pesquisa ainda está em andamento, e no momento se faz com a análise dos Projetos Políticos Pedagógicos disponibilizados pelas escolas e no aguardo das atividades desenvolvidas pelas demais instituições. Entretanto, até onde a análise nos permitiu inferir, afirmamos que os docentes dessas instituições, ainda não se apropriaram do projeto na sua inteireza. Tal fato é elemento maior de pesquisa, neste momento, porque com o intuito de estimular cada vez mais a discussão sobre saúde e ambiente e outros tópicos voltados para o ensino de ciências nas escolas, a pesquisa propõem aproximar os laços entre IFRJ e comunidade escolar do entorno, por conta disso, novas palestras ligadas à saúde ainda serão realizadas nas escolas no decorrer do projeto e um acompanhamento mais amiúde poderá dar conta desse fato que ora, por este ou aquele motivo se apresentou.

Assim sendo, consideramos que todas as pistas, sinais, reações, indiferenças, solicitudes, negações, ou seja, todos esses elementos são passiveis de análises, e como visto no corpo deste artigo, estão de forma clara e verdadeira expostos nas suas mais intensas expressões. Isto porque, para além de acreditarmos, avaliamos que a pesquisa se presta a revelar, trazer à tona o que está submerso.

\section{Agradecimentos}

Agradecemos as diretoras, coordenadoras pedagógicas e professores das quatro escolas estaduais envolvidas na pesquisa, ao IFRJ e CNPq que concederam bolsas de iniciação científica aos alunos envolvidos, e a FAPERJ pelo apoio financeiro relativo ao projeto "As intersecções dos temas saúde e ambiente no ensino formal: análise das práticas docentes e materiais didáticos"

\section{Referências}

CANDEIAS, N.M.F. Conceitos de educação e promoção em saúde. Revista Saúde Pública, v. 31, n. 2, 209-213, 1997.

DÉJOURS, C. A loucura do trabalho. São Paulo: Cortez, 1980.

FONSECA, F. A escola como espaço facilitador para a promoção da saúde e prevenção de riscos. In: Encontro Nacional de Ensino de Ciências da Saúde e do Ambiente, 2008, Niterói. Caderno de Resumos do Encontro Nacional de Ensino de Ciências da Saúde e do Ambiente. Niterói : UNIPLI, 2008. v. 1. p. 19-24.

OMS. Preâmbulo da Constituição da Assembléia Mundial da Saúde, adotada pela Conferência Sanitária Internacional realizada em Nova York (19/22 de junho de 1946) e assinada em 22 de julho de 1946 pelos representantes de 61 Estados, com 
vigor a partir de abril de 1948, não emendada desde então. Disponível em: http://www.who.int/home-page/index.es.shtml. Consultada em 21/02/2008.

BRASIL. Secretaria de Educação Fundamental. Parâmetros Curriculares Nacionais: saúde - Brasília: MEC/SEF, 1997.

PEDROSA, J.I.S. Perspectivas na avaliação em promoção da saúde: uma abordagem institucional. Ciência \& Saúde Coletiva, 9 (3): p.617-626, 2004.

PEREIRA, A L. F. As tendências pedagógicas e a prática educativa nas ciências da saúde. Cad. Saúde Pública, Rio de Janeiro, 19(5):1527-1534, set-out, 2003.

SANTOS, J.L.F.; WESTPHAL, M.F. Práticas emergentes de um novo paradigma de saúde: o papel da universidade. Estud. Av., v.13, n.35, p.71-88, 1999

SEGRE, M.; FERRAZ, F.C. O conceito de saúde. Revista de Saúde Pública, v. 31, n. 5, p. 538-42, 1997.

SEIDL, E.M.F.; ZANNON, C.M.L.C. Qualidade de vida e saúde: aspectos metodológicos e conceituais. Cadernos de Saúde Pública, 20, 580 - 589, 2004.

SÍCOLI, J.L.; NASCIMENTO, P.R. Promoçäo de saúde: concepçöes, princípios e operacionalizaçäo. Interface - Comunicação, Saúde e Educação. 2003; 7:91-112. 